\title{
Finnish Lessons to Help Canadian Students Finish
}

\author{
Theresa A. Papp \\ University of Saskatchewan \\ Saskatoon, Canada
}

\begin{abstract}
The Finnish education reform at first glance appears to be a miraculous transition. However, at closer inspection, there is a myriad of contributing factors that have created the metamorphosis from a country of high unemployment and low education levels to reach iconic and enviable 95\% graduation rates (OECD, 2016; Sahlberg, 2011). This reflective report is juxtaposed to a Canadian context. Finland has invested in universally accessible childhood education, daycare, and free education at all levels. This warrants Canadian policymakers to revisit the Finnish education approach with the potential to improve education attainment levels for all children of Canada.
\end{abstract}

Keywords: Comparative Education; Education reform; Finland; Canada; Aboriginal; Graduation.

\section{Introduction}

When examining the Canadian education system and reviewing the tangible outcomes, such as graduation rates, a beginning point might be to answer the question what is the purpose of school? There could be a plethora of answers to that question. Schools, however, can be identified as powerful influences on youth and if the most simplistic answer to the purpose of education and completing school is to prepare youth for their future role of adults in society, in Canada, there remains a requirement to receive a high school diploma. A high school diploma is considered a stepping stone to a post-secondary degree or diploma which leads to typically higher paying jobs. As a developed country, Canada should be above a 90\% success rate in completing high school. However, Canadian school statistics fall short of that expectation compared to countries such as Finland. It is essential to consider other approaches that have been successful in other countries in an effort to improve graduation rates in Canada for all students. The significance of this report is to present alternative strategies to improve graduation rates accented by a pronounced mandate echoed by all levels of Canadian government to improve education achievement levels.

Many reports attribute Finland's success to the status of the teaching profession, teacher preparation, and the autonomy of the teachers (Sahlberg, 
2001; 2012) that is not refuted. However, this report provides a closer inspection of the complete journey of a child born in Finland to the completion of primary school and upper secondary school presenting many other contributing factors to a child's success that complement the teachers. This reflective report shares less prominently presented findings juxtaposed to Canadian comparatives. Policymakers are invited to stretch the existing Canadian education boundaries and consider alternatives. Implementation of modified variations of the contributors to student success in Finland may improve education levels for students in Canada.

This reflective report will begin by providing a few caveats to guide the reader and set the focus. Next, the reader will be presented with statistics on immigration, taxation comparisons, cost of living, and other myths that repudiate Finland as a country not to be used for comparison purposes to Canada. Following is a presentation of the support systems that exist in Finland and their contribution to the educational outcomes. A comparison will be provided from the Canadian context throughout this report. A discussion and reflection will follow. This report is a timely and noteworthy document that may offer guidance for education administrators, policy planners, and government leaders in the area of education reform.

\section{Caveats}

The following caveats are provided to guide the reader and clarify the focus of this report. Firstly, the Programme for International Student Assessment (PISA) rankings is not the only marker of education achievement. Other methods of assessment such as government statistics on graduation rates and other measurable comparisons provided by the Organization for Economic Cooperation and Development (OECD). The OECD also administers the triennial international PISA survey. OECD presents statistics that analyze and compare data from many countries to set standards and improve the quality of life for people around the world.

Secondly, this report is intended to inform the reader of areas that would improve student education achievement levels. In no way is this paper an intentional comparison of Canadian Aboriginal to Indigenous children in Finland or solely focused on Canadian Aboriginal children. Its purpose is to suggest that school administrators and policymakers consider implementing other approaches to education and pre-education than the conventional methods that have been practiced for decades in Canada without substantial change. Included in this report will be the reference to disadvantaged children that live in poverty. This paper will refer to statistics offered by provincial and federal government documents.

Thirdly, the focus of this paper is solely on provincial school systems either located within the various provinces of Canada or specific reference to the Province of Saskatchewan school statistics. Canada is a vast country represented by ten provinces and three territories each that have independent jurisdiction over their education systems. The Province of Saskatchewan has been chosen to provide a contextual comparison of costs and statistics to put the information into perspective. First Nations reserve schools are not included in this report as they are under the control of the Government of Canada. 
What follows is a brief overview of Finland's education reform and comparative education statistics.

\section{Comparative Education Statistics}

The primary purpose could be the preparation of children to compliment a society by providing them with necessary knowledge and skills to be successful in the 21st Century. The Ministry of Education and Culture (2012) of Finland stated, "The aim of basic education is to support pupils' growth into humanity and into ethically responsible members of society and to provide them with knowledge and skills needed in life" (p. 26).

Finland was a poor agrarian country half a century ago that recognized the urgency to improve its economy. The political parties joined forces, and through consensus, they focused on a recovery plan to rebuild the country by investing in its people through education. In the 1970's, a political decision was made to merge private grammar and civil schools into a nine-year comprehensive municipal school for all children known as peruskoulu (Sahlberg, 2011).

The Finnish rankings in the first PISA survey in 2000 brought Finland's education reform to a worldwide stage. PISA is a survey that assesses 15-yearold students' knowledge in the domains of reading, mathematics, science and problem-solving extrapolating what the pupils have learned in school to unfamiliar scenarios or settings (OECD, 2017). There are critiques presented regarding the accuracy of PISA results, sampling, and fair representation of student scores from the countries. Martino and Rezai-Rashti (2013) reported that large-scale testing is extensively reported with international comparatives without the associated analysis of the socio-economic status and the distribution of education resources that affect students' performance on the results.

Although Finland ranks consistently higher than other countries in the PISA survey, Finland denounces standardized testing and typically rejects assessment practices. The PISA test may be the only formalized test the Finnish students' experience. The first PISA results were released in 2001, and the five cycles that followed in 2003, 2006, 2009, 2012 and 2015 yielded Finland among the top-ranked in the world against 72 countries and economies (OECD, 2017; Reinikainen, 2012). Canada has also maintained rankings in the top ten with the recent 2015 results ranking Finland at five and Canada at seven. Despite the close PISA rankings between Canada and Finland, graduate rates in Canada are sharply lower than Finland (Sahlberg, 2011).

Also, the OECD (2016) report, Education at a Glance 2016, reported that two countries of similar prosperity could have very different education results and demonstrated that higher expenditures in education do not lead to better education outcomes. The United States and the United Kingdom are reported by the OECD (2010b) to "invest heavily in external accountability systems designed to produce more equitable outcomes" (p. 127). OECD (2016) cited the United States invested large amounts of money and ironically resulted in far lower results, ranked at 25, as compared to Finland.

Finland's consistent graduation levels continue as reported that Finland ranked among the highest countries with a 95\% graduation rate (Roy, 2015; Sahlberg, 2011). For comparative purposes, Canada and the United States 
graduation rates were $76 \%$ and $72 \%$ respectively (Sahlberg, 2011). Furthermore, to add another dimension to the Canadian context, the Canadian Aboriginal population 15 years and over that have no certificate or diploma is $44 \%$ (Statistics Canada, 2006). A more recent study revealed that in one Canadian province, Saskatchewan, the graduation rate for Aboriginal students was 32.5\% compared to $82 \%$ of non-Aboriginal students (Pelletier, Cottrell, \& Hardie, 2013). The graduation statistics for Canada are concerning and have triggered provincial and federal mandates to improve education and graduation rates. The following section will provide statistics that address the fallacies commonly argued that Finland is a homogeneous country and thus not appropriate to be compared to Canada.

\section{Myth Busters}

Finland is often considered a homogenous country when compared to countries such as Canada. However, perhaps Finland is not as homogeneous as initially portrayed with the increase in immigration to Finland within the past decades (Holm \& Londen, 2010). Finland has been attracting immigrants from the Middle East and Africa with some Helsinki schools serving a majority of immigrant students (Darling-Hammond \& Rothman, 2015). Statistics Finland (2016) identified the population of Finland was approximately 5.5 million people and immigrants represented $7 \%$ of the total population with the majority Arabic speaking. By comparison, Saskatchewan in 2016 had a population of 1.13 million people, and immigrants represented $8 \%$ of the entire population with the majority from the Philippines (The Canadian Magazine of Immigration, 2017).

Finland is commonly thought to have a high tax rate compared to Canada; therefore, Finland would have more money to invest in education than another country such as Canada. When further investigated, using 2017 tax information, Finland has a minimum national tax rate of $6.25 \%$ with a maximum national rate of $31.5 \%$ and municipal taxes ranging from $16.50 \%$ to $22.50 \%$ for a maximum taxable position of $54 \%$ (PWC, 2017). By comparison, Canada has a minimum federal tax rate of $15 \%$ up to a maximum national rate of $33 \%$ and provincial taxes ranging from $11.50 \%$ to $25.75 \%$ for a maximum total of $58.75 \%$ (PWC, 2017). When compared, Canada has a maximum taxable total of $58.75 \%$ to Finland's maximum taxable rate is $54 \%$. As a nation, depending on the province, Canada collects more tax dollars or very comparable tax dollars as does Finland as a nation implying that there are funds to invest in education in Canada similar to Finland.

The public expenditures on Finnish education represent $5.6 \%$ of Gross Domestic Product (GDP) compared to 6.1\% for Canada (Sahlberg, 2011). When comparing the GDP of Finland and Saskatchewan on a per capita basis, Saskatchewan is comparable to the Canadian average and has more to distribute into the education and day care sector than Finland (Government of Saskatchewan, 2014).

The minimum wage in Saskatchewan until September 30, 2017, is $\$ 10.72$, the lowest in Canada (WageIndicator, 2017). There is no nationally established minimum wage in Finland; however, Statistics Finland (2017) provided a median salary for persons employed in the accommodation and food service industry, the lowest paid industry in Finland, at EUR 2,268 gross earnings which 
are the approximate equivalent to $\$ 3300$ per month. The translated salary would equate to approximately $\$ 20.63$ in Canadian dollars, nearly double what the minimum wage earner receives in Saskatchewan, Canada. The requirements to work in the food and accommodation industry would typically be a high school diploma or a non-graduate. The differences in salaries between the two countries are substantial. Finland people earn nearly $100 \%$ more income in the lowest paying industry. Comparing the cost of living between Saskatoon, the largest populated city in Saskatchewan, to Helsinki, Finland it is found that the consumer prices in Helsinki are $4.22 \%$ higher, and grocery prices in Helsinki are $16.47 \%$ lower while the purchasing power in Helsinki is $18.12 \%$ higher than Saskatoon (Numbeo, 2017).

Also, Finland's population is represented by $7 \%$ immigrants while Saskatchewan's population has $8 \%$ immigrants. Total maximum taxation rates range between the two countries but not that significantly different; however, nationally the lower income earners in Finland has a minimum tax rate of $6.25 \%$ compared to a more than doubled taxation rate of $15 \%$ in Canada. The lowest paying industry in Finland and Canada is the food and accommodation industry, and Finland workers earn twice as much income at over \$20/hour than a Canadian would earn while Finland enjoys more purchasing power and pays less for groceries. The minimum wage of $\$ 10.72$ in Saskatchewan sets the stage for a working poor population that cannot afford the basic needs of shelter and food. The following section compares the education system in Finland to Canada and presents comparatives in finance structure, daycare, and child education.

\section{Finnish versus Canadian schools}

Finland has documented graduation rates for upper secondary school at $95 \%$ (Roy, 2015; Sahlberg, 2012). Over the past decade, PISA scores ranked Finland among the top ten in the world. A myriad of interconnected factors that include social, cultural, pedagogical, student-focused interest, teacher education, school practices, and economic influences contribute to these statistics (Reinikainen, 2012). The following section will provide comparatives between Canada and Finland and discuss paramount influences on educational success in Finland.

\section{Education structure and finance}

All levels of Finland's education, including Finnish universities and polytechnics, are publicly financed and free to all who have completed upper secondary school and desire to continue their studies. Students enter school at the age of seven. Six core content orientations (mathematics, natural sciences, historical-societal, aesthetic, ethical and religious-philosophical) guided by trained educators that will modify the content dependent on the different ages and developmental stages of the Finnish students. The National Curriculum Guidelines on Early Childhood Education and Care in Finland (Stakes, 2004), provides a framework to ensure children experience a balanced development. Children are also encouraged to develop artistic skills through music, drawing, dance, and handicrafts, and educators respect the personal choices made by the children. Once students from Finland complete peruskoulu at grade level nine, the student will decide on a vocational or pre-university education path. Seppala (2014) stated there are no fixed classes or grade levels that represented 
grades 10,11 or 12 . Students would plan their studies based on their interests and career plans. Students may finish their upper secondary education in less than three years as pupils can take classes at other schools or summer school and, with permission, take courses at the University (Vilponen, 2014).

Canada offers publicly accessible school free up to the secondary level. Education is represented by the elementary school, beginning with kindergarten at approximately age five and continuing into secondary education also known as high school, which typically starts at the grade nine level and usually concludes at grade twelve at around age seventeen. Education in Canada is publicly funded and is under the jurisdiction of each of the ten provinces and three territories. Each province and territory will have fixed mandatory class requirements to qualify for a high school diploma. The focus throughout grade school until graduation is academically based. There are a limited number of high schools that offer vocational training options as most trades or vocational schools are at the post-secondary education level. Post-secondary education is the responsibility of the student.

\section{Daycare, Preschool, and Kindergarten}

At first glance, it appears that peruskoulu provides an ultimate learning system for their students with graduation rates to be envied by Canada and other countries around the world. However, upon closer inspection, the successes in upper secondary school may be paved by an investment in pre-school and daycare. Finland children in the age group of 0 to 4 years represent 303,006 of Finland's population as at the end of 2013 representing $5.5 \%$ of the population. The 0 to 4 years age group in Saskatchewan, according to the Government of Canada Statistics Canada (2016), is 62,223 representing 5.5\% of the entire population.

\section{Formal daycare curriculum}

In Finland, learning does not begin at the time of entering grade school at age seven. Children in Finland start their education upon entering daycare as early as age zero under the guidance of trained professional teachers and nurses. Odena (2006) explained that there is a formal curriculum for early childhood education, and this means the children are taught through playing. In a clinical report, Drs. Milteer and Ginsburg (2012) supported the importance of play and identified the contribution of play to the development of social, emotional, cognitive skills and academic influences. Teaching daycare children in Finland is embedded into different activities and phases of the daily routine linking play with learning and developing social skills, language, and physical activity.

Early childhood education in Finland is directed both nationally and by local municipalities. The National Curriculum Guidelines on Early Childhood Education and Care in Finland (Stakes, 2004) is the directive for Early Childhood Education and Care (ECEC) in Finland. This document stated, "ECEC in Finland has two primary goals. One is to fulfill the day care needs of children under school age, and the other is to provide early childhood education" (p. 2). The ECEC curriculum includes guidelines and individualized ECEC plans for each child considering the child's interests, strengths, experiences and identifies any needs for support or guidance. The ECEC plans are developed jointly by the 
professionals of the daycare and the child's parents to direct the child's care and early education goals and will vary depending on the child's age. The collaboration of parents and daycare professionals is to support the child's growth, development, and learning based on the needs of the child and is regularly reassessed providing consistency among staff. The cooperative approach combines staff and parent knowledge of the child to enable early detection of a potential need for support in the areas of learning, development, or growth and to develop a common strategy to assure the child's future success.

\section{Daycare staff education levels}

The 2004 ECEC National curriculum guidelines on early childhood education and care mandate that one-third of the daycare staff to have Bachelors or Masters level education (Stakes, 2004) as well as nurses on staff. Utilizing this professional capacity affords the early diagnosis of special needs and special education. The ECEC directs expert opinions to facilitate assessment, and special supports are implemented to prevent prolonged or accumulating conditions (Stakes, 2004). In implementing ECEC, there is a network of service providers that collaborate to provide services for children and families. These partnerships include educational, social and health authorities, culture and sports organizations, private service providers and various other agencies or organizations (Stakes, 2004).

Child requirements for supports and needs assessments are conducted by nurses and are to identify physical, cognitive, emotional, social, health or other developmental conditions. Doctors are approached only in dire circumstances (Jahnukainen, 2014). Jahnukainen (2014) reported that ADHD is rare in Finland. Children are first assessed by nurses and at an early age. The recommended treatment may suggest behavior modification counseling and other restorative techniques versus a prescription for Ritalin. Hence the Finnish approach is more preventative and curative compared to introducing a drug to treat the behavior.

\section{The cost of daycare}

The City of Helsinki (2014a; 2014b) provided a daycare price list that offers Finland parents daycare at various times of day, overnight and for multiple days for a fee. The cost of childcare is free for the lower income groups in Finland and the fact that the price list includes overnight and multiple days indicates that looking after children in Finland is a 24/7 responsibility. Costs for full-time child care in Saskatchewan are $\$ 603$ per month for infants, \$514 for toddlers and $\$ 473$ per month for preschool in child care centers and slightly less in family child care homes (ECD-ELCC, 2014). By comparison, Finland reported that low-income families access child care and child education for free to a maximum of 233 euros or about \$350 Canadian (European Parliament, 2013).

\section{Political support}

The Province of Saskatchewan had expanded programs to serve more children, increased early childhood workers' salaries, and requested staff to upgrade their formal education qualifications to certification in child care as reported by Eggleton and Keon for the Senate of Canada (2009). A certification 
at Saskatchewan Polytechnic would require 38 weeks of study, approximately nine months, (Saskatchewan Polytechnic, 2017) compared to a Bachelor or Master's degree, requiring four to seven years of study.

The first daycare legislation in Finland, Children's Day Care Act, came into force in 1973 and sanctioned all local municipalities to provide good childcare. In 1996 the act was further updated providing national regulations and legislation regarding child day care and pre-school education (Hannikainen, 2010). All Finnish children under age seven have a right to childcare regardless of family income or parental employment status (European Parliament, 2013). In Finland, compulsory school begins at age seven; therefore, children from age zero to age six may need childcare which demonstrates political support for the children of Finland and their parents.

Comparatively, the political traces of the Canadian history of kindergarten and daycare has been noted to be ambivalent as to its benefits and value, and this attitude has endured since 1820 despite a variety of Head Start programs providing very positive outcomes for children (Prochner, 2000). Howe (2000) further explained the Canadian government's indecisive attitude towards childcare is punctuated by the attitude of "... Early childhood care and education are seen in the slow reaction of the authorities to enact legislation to regulate child care centers, specifically teacher training, teacher-to-child ratios, and health and safety" (p. 295). Neither Canada nor Saskatchewan has a formal curriculum for early childhood education.

\section{Student to teacher ratios compared}

The lack of political support and drastic budget cut in education has resulted in less support staff and substantially higher ratios of students to teachers in some Saskatchewan schools (CUPE Saskatchewan, 2018). Odena (2006) reported the regulations for Finland's child care provide guidelines for children from 0 to 3 years of age have a ratio of 3 adults (1 teacher and 2 nurses) for every 12 pupils. Children aged 3 to 6 years have 3 adults $(1$ teacher and 2 nurses) for every 20 pupils. Kindergarten legislation for some provinces, such as Saskatchewan, does not restrict the class limit (ECD-ELCC, 2014). Seppala (2014) reported that Finland's students in grades 1 and 2 have small classroom sizes consisting of approximately 10 to 15 students. The classroom numbers increase to approximately 20 to 25 students in grade levels 3 and 4 . Lower class sizes provide the Finnish student with an excellent opportunity to learn and adjust to the school program.

For comparative purposes, the Saskatchewan ratio in city centers for kindergarten can be above 25 students to 1 teacher versus 10 students to 1 teacher in Finland (personal communication, K. Teacher, 2016). Although other Canadian provinces identify an optimum size for classrooms to improve education outcomes, the Saskatchewan government had reported that there would be no restriction to class sizes despite reports that the larger cities are bursting with students (Langenegger, 2013). The Saskatchewan 2017-2018 budget lowered education funding by $\$ 145.8$ million resulting in cuts in the classrooms and support staff (Government of Saskatchewan, 2017). At the same time schools are faced with increased enrolments from a sizeable influx of immigrant students, and special needs students have increased where teachers 
need educational assistants in the classroom. Budget cuts resulted in wage rollbacks and layoffs resulting in students' needs are not being met. The decrease in education funding is affecting the quality of education (CUPE Saskatchewan, 2017).

\section{Investing in Canada and Saskatchewan's future}

The Senate of Canada took notice of an OECD report Starting Strong II, (2006) which ranked Canada the lowest investor in early learning and child care programs among 14 countries (OECD, 2006). The OECD recommended Canada become more active in initiatives for early childhood services for children before kindergarten. The Canadian government boasts investing to support children and their families through income tax deductions, Family Allowance, and tax credits. None of the claimed child care investment money is guaranteed to go towards early childhood education and childcare. The Government of Canada has recognized the need for more investment in early childhood learning and child care and in the 2017 budget has allocated funds over the next five years as part of Canada's New Infrastructure Plan (Government of Canada, 2017).

However, Saskatchewan reported children ages 0 to 5 years represent approximately 76,000 children (Government of Canada, 2016). The Saskatchewan Plan for 2017-18 presented by the Ministry of Education identified 889 new childcare spaces with a total of new spaces created in the past ten years to total 6,000 childcare (Government of Saskatchewan, 2017). Based on a projected yearly birth rate in Saskatchewan of approximately 16,000, there appears to be a significant shortfall in child care facilities (Government of Canada, 2016). Although there are more childcare spaces, families are faced with potential sacrifices if childcare services are unavailable or unaffordable.

\section{The Teaching Profession}

Teaching is a highly respected profession that ranks next to medical doctors and dentists in perceived value in Finnish society (Sahlberg, 2011). The education reform in Finland endorsed teacher professional development and researchbased teacher education represented by a minimum of five years of university training (Sahlberg, 2011). Further curricular reform in the 1990's resulted in teachers to be granted self-regulation and focused on teacher professional development through networking adopted from the Alberta Initiative for School Improvement (AISI) program.

There is a dramatic difference in the stature of teachers and teaching, particularly in Saskatchewan. A qualitative research project conducted with teacher participants that had experienced a Finland study tour compared their position in Saskatchewan to the Finnish teachers (Orlowski, 2016). The teacher participants reported that they felt mainstream media and the Saskatchewan government presented teachers in a contrary view to the public as lacking professionalism and the government did not support teachers with budgets focused on saving tax dollars compared to investing in education. Orlowski reported, "All the TP's [teacher participants] expressed discontentment and even frustration at the lack of recognition for the long hours they work" (p. 26). This opinion may be the result of a unilateral attempt by the Saskatchewan government in a 2014 new contract to increase classroom hours for teachers 
which teachers rejected. In general, the public opinion was that teachers were called "complainers or whiners during contract negotiations" (p. 25) and the public considers teaching an easy job. In reality, teachers work hard and even harder now with continuing budget cuts and increasing student number, student needs, and less support staff resulting in not meeting the needs of the students.

Finnish teachers teach approximately 600 hours annually or 4 lessons per day compared to approximately 1080 hours in Canada (Sahlberg, 2011). Finland endorses low teaching hours to provide teachers with the opportunity to engage in school improvement, curriculum planning and personal/professional development (Sahlberg, 2011). Finnish teachers enjoy a significant amount of autonomy with little interference from education administration (Sahlberg, 2011).

Other main distinctions of Finnish teachers versus Canadian teachers include a high degree of public trust of teacher's professional judgment when creating curriculum and assessing students' progress versus provincially standardized curriculum and assessments (Sahlberg, 2011). Alternatively, Orlowski (2016) reported that The Ministry of Education dictates curriculum changes no teacher input. There is also a lack of support provided by the government to implement the changes, and more funds need to be available for professional development. Teachers are expected to make the changes in the curriculum without the support and with already burdening hours for teaching in the classroom. Teachers in Finnish schools are entrusted to plan curriculum and customize their curriculum (Sahlberg, 2011).

The following section provides an overview of the other salient factors that are contributors to the success of Finnish students.

\section{Other Success Contributors: Career Counselling, Block System, and Vocational Options}

A prominent cornerstone in Finnish schools is the importance of career counseling as a compulsory part of the school curricula. All students receive two hours per week of career guidance that also included a two-week work placement (Sahlberg, 2011). The Saskatchewan curriculum offers Career Education beginning in grades six to nine for a total of 30 hours per academic year. The curriculum document recognized "one of the realities for Saskatchewan teachers of Career Education is minimal professional preparation and training in the subject area" (Saskatchewan Curriculum, 2008, p. 1) implying that the implementation of the curriculum could vary dramatically from teacher to teacher and school to school. Saskatchewan curriculum offers 50\% less career counseling and no work placements for their students compared to Finland students.

Research has indicated that school counseling interventions have a positive effect on students with "significant effect sizes for interventions at the elementary, middle and high school levels" (Whiston, Tai, Rahardja \& Eder, 2011, p. 48). Further research conducted by Carey, Harrington, Martin, and Hoffman (2012) found that career counseling decreased discipline rates and increased attendance and academic proficiency rates further endorsing the 
improvements to student outcomes and the need to invest school budgets into career counselors.

The Finnish students construct their learning path and proceed through upper-secondary education at their own pace and select courses best suited for their vocational track or in preparation for university or polytechnic schooling (Sahlberg, 2011). This approach creates relevance and choice for the students. Researchers have stated that students drop out of school because they do not see the relevance of the classes they are taking (Demmert, 2011; Foley, 2012).

Sahlberg (2011) reported that the Finnish upper secondary schools once had two semesters which were replaced by six- to seven-week periods to take two or three courses at a time in what is considered a modular or block system. The block system permits more significant segments of time for instruction offering an improved learning experience for the students resulting in a better understanding of the course material. Teachers and students have the time to build relationships which also improves the learning experience. Utilizing the block system, students attend fewer classes in a day and spend more time in each class allowing for more focus and enhanced learning while the pace is individualized (Anderson \& Walker, 2015; Marchant \& Paulson, 2001).

Typically, high schools implement a two-term academic system with six or more classes taken each term in 50 minutes time periods. The short time to cover material and teachers are attending to the needs of potentially over 150 different students creating a challenging scenario to get to know your students and build relationships while maximizing the learning. Some Canadian schools have also migrated to a block system or modified block system with reported success in credit completion rates; however, the two-term format per academic year prevails in most schools.

Students complete Peruskoulu at grade level nine, and at that point, the student will decide on a vocational or pre-university education path. The opportunity to have a choice is empowering and addresses the reality that not all students are academically inclined, and some students prefer hands-on learning or are more mechanically inclined. The vocational option also prepares students to prepare for the labor force and transition from the education system with knowledge and skills to enter into employment. There are a limited number of high schools that offer vocational training options as most are at the postsecondary school level.

It would appear that career counseling, work placement, and planning courses according to a career path are also contributors to student success in Finland. The block system, as well as a vocational option in addition to pure academic are favorable for graduation success.

\section{The Cost of Poverty in Canada}

Another lens to consider when endorsing education reform, particularly beginning with daycare and early childhood education, is the cost of poverty to Canada taxpayers. Children that live in poverty experience disparities that affect their education and health based on a lack of socioeconomic resources strengthening the need for early childcare and education (Milteer \& Ginsburg 2012). Interventions in early childhood with early education and social enrichment are reported to compensate for the disadvantages those children in 
poverty experience (Niles, Byers, \& Kruegar, 2007). Niles et al. reported the importance early childhood programs, such as Head Start, provide for children to develop social competence, development of attitudes, self-esteem, physical health, nutrition, and cognitive development. Without an intentional intervention to improve early childcare and early childhood education, what occurs is a vicious cycle of low education levels resulting in low paying employment. Poverty continues and places these people among the working poor resulting in disadvantaged children growing up in poverty. Low minimum wages and inflated living costs prohibit the ability to meet the costs of living.

Poverty costs Canada 72-84 billion dollars annually, and taxpayers carry that burden (Canada without Poverty, 2016). The Conference Board of Canada in its most recent report on economy noted that Canada was last ranked in fifth position according to its economy ranking against other peer countries and now ranks 15 out of 17 highest in child poverty with one in seven Canadian children living in poverty. A wealthy country, such as Canada, should not have such levels of poverty. Canada Without Poverty (2014) cited the Food Banks Canada reported nearly 900,000 Canadians used food banks each month and poverty imposed $\$ 7.6$ billion on Canada's health care system. In line with the Finland approach, the report indicated that for every $\$ 1$ invested in early years before age six will save Canada $\$ 9$ in future spending on health care, welfare, unemployment, addictions, and justice systems. These statistics strengthen the argument to invest in children through early childcare and early childhood education.

The Conference Board of Canada (2014) reported that one in seven Canadian children live in poverty and Aboriginal children in Canada are 2.5 times more likely to live in poverty than non-Aboriginal children (Macdonald \& Wilson, 2013). Aboriginal children fall exponentially behind non-Aboriginal children in the indicators of family income, education attainment, and are the highest group to experience homelessness ranking 15 out of 17 peer countries only to be surpassed by Italy and the United States (Macdonald \& Wilson, 2013). Denmark and Finland have the lowest child poverty rate (The Conference Board of Canada, 2014). Douglas and Gingrich (2009) reported that Saskatchewan has the third highest provincial child poverty in Canada of which $45 \%$ of Aboriginal children live in low-income families and of those children one-third live in situations wherein their families are full-time and full-year employed. The statistics of the growing Aboriginal population and referenced Ottawa-based studies indicated that if Aboriginal education levels could match non-Aboriginal education levels, Canada could add \$170-billion to its economy (Levesque, 2011).

Recommendations from OECD suggest that pre-primary education is valuable for education performance and governments should subsidize and invest in children at an early age especially for disadvantaged families to ease the financial burden (OECD, 2014). The PISA report of 2012 indicated that preprimary education attendance for more than one year raised the mathematics scores by 53 points higher than the students that did not attend pre-primary school (OECD, 2014). At an early age, children are expected to benefit exponentially from early childhood education. Investing in early daycare and early childhood education would have a positive impact on the economy of Canada and Saskatchewan. 


\section{Conclusion}

Comparing Finland to Saskatchewan based on its population, immigrant statistics, GDP, and taxation found similarities. The Finnish education model may be a prototype worth consideration as it embraces diverse students' abilities and equity for all students. The Finnish education reform at first glance appears to be a miraculous transition. However, at closer inspection, the enviable $95 \%$ graduation rates of Finland's students begin with Finnish strategies that focus on the foundation to education starting with childcare and early childhood education. The Finnish education approach is sensible, purposeful and thoughtful for the best interests of the students to achieve academic completion at the minimal upper-secondary levels.

The Finnish daycare centers are free to low-income families or at a modest cost. The daycare centers set the stage for educational success and are housed with professionally trained teachers with a minimum of a Bachelor or Masters of Arts in Education or Bachelor of Social Sciences levels, to provide Finnish children with directed and guided curriculum and nurses to wholistically attend to the child's needs. Qualified nurses offer early assessments of children to identify special support required in physical, cognitive, emotional or social development.

A national curriculum and directives from ECEC guide daycare and early education providing the best possible beginnings for young children from age zero until entering peruskoulu at age seven. The low ratios of children to qualified, trained professional teachers and nurses in the daycare is essential to providing the ability to identify the need for special support in the children's physical cognitive, emotional or social development. Reports presented earlier in this paper endorse the importance of investing in children, especially for disadvantaged children that live in poverty or with low socioeconomic backgrounds.

The Finnish education system embraces a student-focused approach through preventative special education, individual learning plans for students that begin as early as daycare. Support for learning includes nutritious free school meals, health services, psychological counseling, and student guidance (Sahlberg, 2011). Teaching strategies offer research-based educational practices and creative teaching. The OECD (2014) applauds Finland's daycares for the early detection mechanisms and individualized periodic evaluations allowing identification of struggling students and support mechanisms put in place so students can continue their education without getting stuck or falling behind their peers. The Finnish way also consists of an option to graduate from upper secondary with either an academic or vocational training. Regular career counseling, work placement experience, a block or modified block semester system, curriculum that is experiential, experimental, and problem-based, as well as shared responsibility and trust in the teachers, contribute to the students' success (Sahlberg, 2011).

Finland has focused its resources on investing in its people through early childcare and child education through as well as nationally funded Peruskoulu and higher education while Canada ranks at the bottom of the list when it comes to investing in its children (OECD, 2006). Finnish teachers are highly trained in 
content, curriculum, and education strategies are research-based which contributes to the educational foundation. With the inclusion of vocational upper-secondary as an alternative to general academics, students are educated to immediately contribute to the Finnish society or continue to polytechnic or university. The Finnish education system provides successful school options for all students.

A concerted political approach that Finland took to invest in its people was an exemplary example that could potentially benefit all Canadians. A revised Canadian teacher education approach that extends to the master's level and professional development schools would within a few decades replenish the education system with new and improved teaching strategies.

As with any business; you need to spend money to make money. Perhaps Canada should refocus allocations of the taxpayers' dollars to invest in universally accessible daycare, free education at all levels, revised teacher education and in a few decades, reap the rewards of a better overall society with more viably employed Canadians paying taxes and contributing to society versus requiring social assistance. Continuing to take the same approaches and expect different results has not been successful to this point. Sahlberg (2011) had stated that Finland had learned from Canada, the United States, and the United Kingdom to develop their school strategy. Canada can revisit what Finland has learned from us and collectively join forces provincially and federally to build a better Canada by investing in its people and most importantly investing in the children of Canada.

\section{References}

Anderson, D. M., \& Walker, M. B. (2015). Does shortening the school week impact student performance? Evidence from the four-day school week. Education Finance and Policy 314-349. doi: 10.2139/ssm.2008999.

Canada without Poverty. (2016). Poverty: Just the facts. Retrieved from http://www.cwp-csp.ca/poverty/just-the-facts/

Canada without Poverty. (2014). Poverty: Just the facts. Retrieved from http://www.cwp-csp.ca/poverty/just-the-facts/

Carey, J., Harrington, K., Martin, I., \& Hoffman, D. (2012). A statewide evaluation of the outcomes of the implementation of ASCA National Model school counseling programs in rural and suburban Nebraska high schools. American School Counselor Association 16(2), 100-107. doi: /10.1177/2156759x0001600202

City of Helsinki. (2014a). Social Services Department, Child Day Care Fees. Retrieved from http://www.hel.fi/wps/wcm/connect/aa2dac4c-f7c4-48dc-b60c75608986f3ac/Asiakasmaksutiedote01082012.EN.pdf?MOD=AJPERES\&CACHE ID=aa2dac4c-f7c4-48dc-b60c-75608986f3ac

City of Helsinki. (2014b). Day Care and Education. Retrieved from http://www.hel.fi/www/Helsinki/en/day-careeducation/comprehensive/what-how/

CUPE Saskatchewan. (2017, March). Provincial budget means big cuts and tough decisions for school divisions, says CUPE. Retreived from https://sk.cupe.ca/2017/03/27/provincial-budget-means-big-cuts-and-toughdecisions-for-school-divisions-says-cupe/

Darling-Hammond, L., \& Rothman, R. (2015). Teaching in the flat world: Learning from high-performing systems. New York, NY: Teachers College, Columbia University. doi: 10.7202/1039642ar 
Demmert, W. G. (2011). What is culture-based education? Understanding pedagogy and curriculum. In J. Reyhner, W. S. Gilbert \& L. Lockard (Eds.). Honoring our heritage: Culturally appropriate approaches to Indigenous education (pp. 1-9). Flagstaff, AZ: Northern Arizona University. doi: 10.1177/117718011100700210

Douglas, F., \& Gingrich, P. (2009). Child and Family poverty in Saskatchewan report. Ottawa, ON: Canadian Centre for Policy Alternatives. Retrieved from http://www.campaign2000.ca/reportCards/provincial/Saskatchewan/2009Po vertyReportCard.pdf

Early Childhood Development Canada (2014). Public investments in early childhood education and care in Canada 2010. Retrieved from http:/ / www.ecdelcc.ca/eng/ecd/ececc/page12.shtml

Eggleton, A., \& Keon, W. J. (2009). Early childhood education and care. Next steps. Senate of Canada standing committee on social affairs, science and technology. Ebrary Inc.: Canada Parliament. Retrieved from http://site.ebrary.com.cyber.usask.ca/lib/usask/reader.action?docID $=10325545$ \&ppg $=1$

European Parliament. 2013. Directorate-general for internal policies. Culture and education: Quality in early childhood education and care. Retrieved from http://www.europarl.europa.eu/RegData/etudes/etudes/join/2013/495867/I POL-CULT_ET(2013)495867(ANN01)_EN.pdf

Foley, D. (2012). Teaching entrepreneurship to Indigenous and other minorities: Towards a strong sense of self, tangible skills and active participation within society. Journal of Business Diversity 12(2), 59-74.

Government of Canada. (2017). Budget 2017: Building a strong middle class. Retrieved from http:// www.budget.gc.ca/2017/docs/plan/chap-02-en.html

Government of Canada. (2017). Births, estimates, by province and territory. Retrieved from http:// www.statcan.gc.ca/tables-tableaux/sum-som/101/cst01/demo04aeng.htm

Government of Saskatchewan. (2017). Meeting the challenge: Provincial budget 2017-18. Retrieved from http:/ / finance.gov.sk.ca/budget2017-18

Government of Saskatchewan. (2014). Saskatchewan Provincial Budget 14-15. Steady Growth. Retrieved from http:// finance.gov.sk.ca/budget2014-15/201415SKProvincialBudget.pdf

Hannikainen, M. (2010). 1 to 3-year-old children in day care centres in Finland: An overview of eight doctoral dissertations. International Journal of Early Childhood (42) 101-115. doi: 10.1007/s13158-010-0015-5

Holm, G. \& Londen, M. (2010). The discourse of multicultural education in Finland: Education for whom? Intercultural Education 21(2), 107-120. doi: $10.1080 / 14675981003696222$

Howe, N. (2000). Early childhood care and education in Canada: An overview and future directions. In L. W. Prochner \& N. Howe (Eds.). Early childhood care and education in Canada. (pp. 19-38). Vancouver, BC: UBC Press. doi: 10.1007/978-94024-0927-7_35

Jahnukainen, M. (2014, August). Inclusive and special education in the Finnish education system- findings from comparative studies and the latest reform 2010-2012. Presented at University of Helsinki, Palmenia Centre for Continuing Education, Helsinki, Finland.

Laukkanen, R. (2006, September). Finnish strategy for high-level education for all. Presented at the conference of Educational Systems and the Challenge of improving results. Lausanne, Switzerland.

Langenegger, S. (2013, March 13). Province won't limit classroom sizes, minister says. CBC News: The Canadian Press. Retrieved from 
http://www.cbc.ca/news/canada/saskatchewan/province-won-t-limitclassroom-sizes-minister-says-1.1408425

Levesque, D. (2011, June 21). Why aboriginal education is our business. Globe and Mail. Retrieved from http://www.theglobeandmail.com/commentary/whyaboriginal-education-is-our-business/article583799/

Macdonald, D., \& Wilson, D. (2013). Poverty or prosperity: Indigenous children in Canada. Ottawa, ON: Canadian Centre of Policy Alternatives.

Marchant, G. J., \& Paulson, S. B. (2001). Differential school functioning in a block schedule: A comparison of academic profiles. The High School Journal 84(4), 12-20. doi:10.1353/hsj.2001.0011

Martino, W., \& Rezai-Rashti, G. (2013, September). "Gap talk" and the global rescaling of educational accountability in Canada. Journal of Education Policy 28(5), 589-611. doi: 10.1080/02680939.2013.767074

Milteer, R. M. \& Ginsburg, K. R. (2012). The importance of play in promoting healthy child development and maintaining strong parent-child bond? Focus on children in poverty. Pediatrics (129)1, 204-213. doi: 10.1542/peds.2011-2953

Ministry of Education and Culture. (2012). Education and Research 2011-2016: A development plan. Reports of the Ministry of Education and Culture, Finland 2012:3. Retrieved from https://rritrends.resagora.eu/uploads/22/Education\%20and\%20research\%20development\%20plan Finland.pdf

Niemi, H. (2012). The societal factors contributing to education and schooling in Finland. In H. Niemi, A. Toom \& A. Kallioniemi (Eds.). The miracle of education: The principles and practices of teaching and learning in Finnish schools (pp. 19-38). Rotterdam: Sense Publishers. doi: 10.1007/978-94-6091-811-7_2

Niles, M. D., Byers, L., \& Kruegar, E. (2007). Best practice and evidence-based research in Indigenous early childhood intervention programs. Canadian Journal of Native Education 30(1), 108-125.

Numbeo. (2017). Cost of living comparison. Retrieved from https://www.numbeo.com/cost-ofliving/compare_cities.jsp?country1=Canada\&country2=Finland\&city1=Saskato on\&city $2=$ Helsinki

Odena, P. (2006) Finland early childhood education. Retrieved from http://www.xtec.cat/ ccols/finlandia/serveis/services.htm

OECD. (2006). Starting strong II. Paris, France: Organization for Economic Co-operation and Development. Retrieved from http://www.oecd.org/newsroom/37425999.pdf

OECD. (2010a). Finland: Slow and steady reform for consistently high results. Paris, France: Organization for Economic Co-operation and Development. Retrieved from http:// www.oecd.org/pisa/pisaproducts/46581035.pdf

OECD. (2010b). Education at a glance 2010: OECD indicators. Paris, France: Organization for Economic Co-operation and Development. Retrieved from http://www.oecd.org/edu/skills-beyondschool/educationataglance2010oecdindicators.htm

OECD. (2014). PISA 2012 results in focus. What 15-year-olds know and what they can do with what they know. Paris, France: Organization for Economic Co-operation and Development. Retrieved from http://www.oecd.org/pisa/keyfindings/pisa-2012-results-overview.pdf

OECD. (2016). Education at a glance 2016: OECD indicators. Paris, France: Organization for Economic Co-operation and Development. Retrieved from http://www.oecd.org/education/skills-beyond-school/education-at-a-glance2016-indicators.htm 
OECD. (2017). PISA 2015 results in focus. Paris, France: Organization for Economic Cooperation and Development. Retrieved from http://www.oecd.org/pisa/pisa2015-results-in-focus.pdf

Orlowski, P. (2016). Saskatchewan teachers and a study abroad experience in Finland: "I love how the Finns respect their teachers!" Journal of Educational Administration and Foundations 25(3), 17-37.

Pelletier, T., Cottrell, M., \& Hardie, R. (2013). Improving education and employment outcomes for First Nations and Metis People. Saskatoon, SK: Saskatchewan Educational Leadership Unit.

Prochner, L. (2000). A history of early education and child care in Canada, 1820-1966. In L. W. Prochner \& N. Howe (Eds.). Early childhood care and education in Canada. (pp. 22-62). Vancouver, BC: UBC Press.

PWC Worldwide Tax Summaries. (2017). Personal income tax rates for resident individuals. Retrieved from http://taxsummaries.pwc.com/ID/Finland-Individual-Taxeson-personal-income

Reinikainen, P. (2012). Amazing PISA results in Finnish comprehensive schools. In H. Niemi, A. Toom \& A. Kallioniemi (Eds.) The miracle of education: The principles and practices of teaching and learning in Finnish schools (pp. 3-18). Rotterdam: Sense Publishers. doi: 10.1007/978-94-6091-811-7_1

Roy, V. (2015, August 24). 10 countries with the highest high school graduation rates. Insider. Retrieved from http://www.insidermonkey.com/blog/10-countrieswith-the-highest-high-school-graduation-rates-366734/8/

Sahlberg, P. (2011). Finnish lessons: What can the world learn from educational change in Finland? New York, NY: Teachers College Press, Columbia University.

Sahlberg, P. (2012). Quality and equity in Finnish Schools. School Administrator 69(8), 2730.

Saskatchewan Polytechnic. (2017). School of human services and community safety: Early childhood education certificate. Retrieved from http://saskpolytech.ca/programs-and-courses/programs/Early-ChildhoodEducation-Certificate.aspx

Saskatchewan Curriculum. (2008). Education: The future within us. Career education. Retrieved from https://curriculum.gov.sk.ca/webapps/moe-curriculumBBLEARN/index.jsp?lang=en\&subj=career_education\&level $=6$

Seppala, T. (2014, August). Finnish education system. Presented at University of Helsinki, Palmenia Centre for Continuing Education, Helsinki, Finland.

Stakes. (2004). National curriculum guidelines on early childhood education and care in Finland. Prepared for Terveyden Ja Hyvinvoinnin Laitos Finland. Retrieved from http://www.thl.fi/thl-client/pdfs/267671cb-0ec0-4039-b97b-7ac6ce6b9c10

Statistics Canada. (2006) Saskatchewan (Code47) (table). Aboriginal Population Profile. 2006 Census. Statistics Canada Catalogue no. 92-594-XWE. Ottawa, ON: Statistics Canada. Retrieved from http://www12.statcan.ca/census-recensement/2006/dp-pd/prof/92594/index.cfm?Lang=E

Statistics Canada. (2008, January) Aboriginal peoples in Canada in 2006: Inuit, Metis, and First Nations, 2006 Census. The Daily. Ottawa, ON: Statistics Canada Retrieved from http://www.statcan.gc.ca/daily-quotidien/080115/dq080115a-eng.htm

Statistics Canada. (2013, May). 2011 National household survey: Aboriginal Peoples in Canada: First Nations People, Metis and Inuit. The Daily. Ottawa, ON: Statistics Canada. Retrieved from http://www.statcan.gc.ca/dailyquotidien/130508/dq130508a-eng.htm

Statistics Finland. (2016). Population by Region, Country of birth, Sex, Year and Age. Retrieved from http://pxnet2.stat.fi/PXWeb/pxweb/en/StatFin/StatFin_vrm_vaerak/040_v 
aerak_tau_103.px/table/tableViewLayout1/?rxid=3227d364-55c9-4998-b694f2710c76fd6d

Statistics Finland. (2017, April 6). Median earnings of wage and salary earners. Retrieved from http://www.stat.fi/til/pra/2015/pra_2015_2017-04-06_tie_001_en.html

The Canadian Magazine of Immigration. (2017). Saskatchewan Immigration: Immigrants landed in Saskatchewan (2000-2015). Retrieved from http://canadaimmigrants.com/saskatchewan-immigration-by-country/

The Conference Board of Canada. (2014). Child poverty. Retrieved from http://www.conferenceboard.ca/hcp/details/society/child-poverty.aspx

Viliponen, S. (2014). Assessment in Finnish schools. Presented at University of Helsinki, Palmenia Centre for Continuing Education, August 20, 2014.

WageIndicator. (2017). Minimum wages in Canada. Retrieved from http://www.wageindicator.org/main/salary/minimum-wage/canada

Whiston, S. C., Tai, W. L., Rahardja, D., \& Eder, K. (2011). School counseling outcome: A meta-analytic examination of interventions. Journal of Counseling \& Development 89(1), 37-55. doi: 10.1002/j.1556-6678.2011.tb00059.x

Young, L., Levin, B., \& Wallin, D. (2014). Understanding Canadian schools: An introduction to educational administration ( $5^{\text {th }}$ ed.). Retrieved from http://homepage.usask.ca/ dcw130/understandingcanadianschools5.html 